\title{
Dissociated Response and Clinical Impact in Patients Treated With Nivolumab Monotherapy
}

\section{Yuki Sato ( $\nabla$ yuki1130sato@gmail.com )}

Kobe City Medical Center General Hospital https://orcid.org/0000-0002-7829-7524

\section{Takeshi Morimoto}

Hyogo Ika Daigaku

\section{Shigeo Hara}

Kobe City Medical Center General Hospital: Kobe Shiritsu Iryo Center Chuo Shimin Byoin

\section{Kazuma Nagata}

Kobe City General Hospital: Kobe Shiritsu Iryo Center Chuo Shimin Byoin

\section{Kazutaka Hosoya}

Kobe City General Hospital: Kobe Shiritsu Iryo Center Chuo Shimin Byoin

\section{Atsushi Nakagawa}

Kobe City Medical Center General Hospital: Kobe Shiritsu Iryo Center Chuo Shimin Byoin

\section{Ryo Tachikawa}

Kobe City General Hospital: Kobe Shiritsu Iryo Center Chuo Shimin Byoin

\section{Keisuke Tomii}

Kobe City General Hospital: Kobe Shiritsu Iryo Center Chuo Shimin Byoin

\section{Short Report}

Keywords: dissociated response, mixed response, nivolumab, immunotherapy, immune checkpoint inhibitor, non-small cell lung cancer

Posted Date: February 4th, 2021

DOl: https://doi.org/10.21203/rs.3.rs-162033/v1

License: (c) (i) This work is licensed under a Creative Commons Attribution 4.0 International License. Read Full License

Version of Record: A version of this preprint was published at Investigational New Drugs on February 10th, 2021. See the published version at https://doi.org/10.1007/s10637-021-01077-7. 


\section{Abstract}

\section{Objectives}

Immune checkpoint inhibitors (ICls) are effective for previously treated patients with advanced non-small cell lung cancer (NSCLC). However, an unconventional response pattern is sometimes encountered. A dissociated response (DR), characterized by some lesions shrinking and others growing, has been recognized with $\mathrm{ICl}$ treatment. In this study, we examined the characteristics and treatment outcomes of DR in previously treated NSCLC patients, receiving nivolumab monotherapy.

\section{Patients and Methods}

We conducted a retrospective cohort study of previously treated patients with advanced NSCLC who received nivolumab. We assessed the tumor response of each organ using the Response Evaluation Criteria in Solid Tumors (RECIST) criteria at the first radiologic evaluation. We investigated treatment outcome and compared overall survival using the Kaplan-Meier Method and log-rank tests. Further, we conducted the same analysis in patients who had previously received chemotherapy or tyrosine kinase inhibitor therapy in our hospital.

\section{Results}

Between April 2016 and September 2018, 107 patients who received nivolumab fulfilled the inclusion criteria. Of them, 5 (5\%) patients showed a DR. There were no specific differences in characteristics between DR and non-DR cases. Patients showing DR had significantly longer overall survival than those showing concordant progressive disease ( 46.9 vs. 8.2 months, $p=0.038$ ). The frequencies of DR in the $\mathrm{ICl}$, chemotherapy, and tyrosine kinase inhibitor-treated cohorts were $5 \%, 1 \%$, and $4 \%$, respectively.

\section{Conclusion}

DR was uncommon, but this presented a distinctive pattern of nivolumab response. Some patients might benefit from continuing nivolumab therapy and may achieve a longer overall survival.

\section{Background}

Lung cancer is the leading cause of cancer-related deaths worldwide [1]. Non-small cell lung cancer (NSCLC) accounts for approximately $80 \%$ of all lung cancers, and in most cases is unresectable and metastatic at the time of initial diagnosis [2]. Recently, immune checkpoint inhibitors (ICls), which inhibit the programmed cell death 1 (PD-1)/programmed cell death ligand 1 (PD-L1) axis, have demonstrated impressive efficacy in patients with advanced NSCLC. Nivolumab (Bristol-Myers Squibb, Lawrenceville, NJ, USA) has been approved as a standard treatment option for previously treated NSCLC after accumulation of data from the CheckMate-017 and CheckMate-057 clinical studies [3,4]. 
The response patterns of tumors treated with ICls may differ from those of tumors treated with conventional chemotherapeutic agents or targeted therapies, owing to their unique mechanism of action [5]. First, an initial flare-up followed by tumor shrinkage, defined as pseudoprogression, has been reported $[6,7]$. Second, rapid tumor progression following $\mathrm{ICl}$ administration, defined as hyperprogression, has also been described $[8,9]$. Finally, previous reports have recognized the occurrence of a 'mixed tumor response' phenomenon in some patients, whereby some lesions decrease in size and others grow $[10,11]$. These heterogeneous response patterns of individual lesions in the same patient have been defined a "dissociated response (DR)" [12]. This atypical response raises the confusion of stopping or continuing $\mathrm{ICI}$ treatment. To date, there are limited data available on the incidence of $\mathrm{DR}$, and its clinical significance has not been fully understood or investigated [13].

Thus, in this study, we aimed to demonstrate the prevalence and clinical course of patients exhibiting a DR following treatment with nivolumab and to provide insight on how to potentially improve the management of this group of patients.

\section{Methods}

\section{Patient inclusion criteria}

We retrospectively analyzed patients with previously treated advanced NSCLC, who received nivolumab monotherapy in the Kobe City Medical Center General Hospital between April 2016 and September 2018 (Figure 1). Patients without any measurable lesions or those whose response to treatment was not evaluated were excluded. Patients who reported never having smoked were defined as non-smokers, those who had smoked within 1 year of diagnosis were categorized as current smokers, and the remaining patients were considered former smokers. All patients were classified on the basis of their clinical stage according to the 8th edition TNM classification criteria [14]. Overall survival (OS) was defined as the period from the day of commencement of nivolumab treatment until death from any cause or the end of the follow-up period. The cutoff date for data collection was December 31, 2020. We isolated tumor DNA from various specimens and analyzed the mutational status of the epidermal growth factor receptor (EGFR) gene at exons 18-21 using the peptide nucleic acid-locked nucleic acid polymerase chain reaction clamp method, as described previously [15]. Anaplastic lymphoma kinase $(A L K)$ translocation was assessed by immunohistochemistry or fluorescence in situ hybridization breakapart probes, as described previously [16]. PD-L1 tumor proportion score (TPS) was evaluated by the 22C3 assay [17]. This study was approved by the Ethics Review Board or Institutional Review Board of each participating institute (zn190108). Informed consent was not required owing to the retrospective nature of the study. Tumors were assessed according to two categories: RECIST version 1.1 and iRECIST criteria, which were used in trials to evaluate the efficacy of immunotherapeutics [18,19]. A durable clinical benefit was defined as the duration of complete response (CR)/partial response (PR) (the sum of the longest diameter [SLD] of the target lesions was decreased by at least $30 \%$ from the baseline)/stable disease (SD) over 6 months [20]. 


\section{Definition of DR}

The DR was previously described as a concomitant decrease in tumoral elements and an increase in other elements $[12,13,21]$. Importantly, no standardized definition of DR exists in the currently available literature. To extract patients with an apparent DR, we defined the specific criteria described below. We reviewed baseline radiographic data and the first computed tomography/magnetic resonance imaging (CT/MRI) results (performed between 6 to 12 weeks after commencement of nivolumab monotherapy), and evaluated measurable lesions per organ and decided its response. Measurable lesions were defined as lesions measuring over $10 \mathrm{~mm}$ in longest diameter or over $15 \mathrm{~mm}$ in short axis diameter for lymph nodes. We examined the tumor response by organs by selecting up to two measurable lesions in one organ. We defined the DR according to the following criteria: 1) patients who have both CR/PR organs and progressive disease (PD, at least a $20 \%$ increase and at least $5 \mathrm{~mm}$ from the nadir in the SLD of the target lesions) simultaneously; and 2) patients who had all CR/PR organs but with the appearance of new lesions or apparent deterioration of unmeasurable lesions. All patients received CT scans within 30 days before commencing nivolumab treatment. Lesions treated with concomitant radiation therapy were excluded from this analysis. All radiological images were evaluated by three independent specialists (pulmonologist and radiologist). In cases of disagreement, the radiographic data were re-examined until a consensus was reached through central review.

\section{Pathological analysis of the DR site}

We collected pathological specimens of progressive lesions in patients with DR and compared these with the primary lesions. Hematoxylin and eosin-stained sections were evaluated by two experienced pathologists.

\section{Comparison analysis of cytotoxic chemotherapy and tyrosine kinase inhibitor therapy}

To clarify the pattern of DR incidence across treatments, we retrospectively analyzed patients who were treated with a first-line cytotoxic chemotherapy agent or first-line EGFR tyrosine kinase inhibitor (TKI) in the Kobe City Medical Center General Hospital between April 2016 and September 2018. We reviewed patients with a DR using the definition described above.

\section{Statistical analysis}

Continuous variables were analyzed using the Student's $t$-test. Dichotomous variables were analyzed using Pearson's $\chi^{2}$ or Fisher's exact test, as appropriate. Kaplan-Meier's method was used to estimate survival outcomes, which were compared using the log-rank test between the groups. A $P$-value of $<0.05$ indicated statistical significance. We conducted the statistical analyses using JMP 11 software (SAS Institute, Cary, NC, USA).

\section{Results}




\section{Patient characteristics and treatment outcome}

Of the 114 patients who were previously treated for advanced NSCLC and who received nivolumab therapy, 7 patients were excluded from the study because they did not have RECIST-defined measurable lesions or they were not adequately evaluated for tumor response (Figure 1). Finally, 107 patients were included in the study; the patients' characteristics are summarized in Table 1. The mean age of included patients was 68.2 years, and most patients were men (72\%), had a history of smoking (75\%), Eastern Cooperative Oncology Group performance status (ECOG PS) of 0 or 1 (93\%), and adenocarcinoma histology (74\%). The total objective response by RECIST criteria was $22 \% ; 19 \%$ of the patients had SD, and $59 \%$ had PD. At the time of analysis, 47 OS events (44\%) had occurred. The median OS and estimated 1 -year OS rate were 17.4 months and $58 \%$, respectively.

\section{Characteristics and treatment course of cases with DR}

DR was observed in 5 patients (5\%). The comparison between DR and non-DR patients revealed no significant differences in the patients' characteristics (Table 1). Treatment course and a representative CT scan of patients with DR are shown in Figure 2.

Patient No. 6 was a 68-year-old man with advanced lung adenocarcinoma (Figure 2A). He started nivolumab as a second-line therapy. After the four cycles of nivolumab treatment, his primary lesion reduced in size (33 $\mathrm{mm}$ to $22 \mathrm{~mm}$ ), although a new metastatic lesion $(10 \mathrm{~mm})$ in his brain was detected on the MRI scan; therefore, DR was diagnosed. His RECIST-defined tumor assessment was PD due to the new lesion and unconfirmed progressive disease (iUPD) by the iRECIST criteria. Nivolumab treatment was continued; thereafter, his tumor remained stable (iUPD by the iRECIST criteria). After 21 cycles of nivolumab, he developed immune-related diarrhea, and nivolumab was permanently interrupted. His tumors remained stable. After 729 days of nivolumab treatment, he experienced iPD by the iRECIST criteria (PD in primary lesion and brain metastasis).

Patient No. 28 was a 53-year-old woman with advanced lung adenocarcinoma. She began nivolumab as a third-line therapy (Figure 2B). After 5 cycles of nivolumab, her primary lesion reduced in size; however, her axial lymph node was enlarged (minimal diameter was $15 \mathrm{~mm}$ ), and DR was diagnosed. Her RECISTdefined tumor response was PD, and her iRECIST-defined tumor assessment was iUPD. Nivolumab treatment was continued for another 6 cycles, until treatment was discontinued because of the onset of immune-related diarrhea. Her tumor remained stable (iUPD by iRECIST criteria). After 234 days of nivolumab treatment, the tumors were radiologically stable, but her serum levels of carcinoembryonic antigen (CEA) and cytokeratin-19-fragment (CYFRA) were elevated. Her attending physician diagnosed the condition as clinical PD, and she started fourth-line chemotherapy.

Patient No. 40 was an 80-year-old man with advanced lung adenocarcinoma (Figure 2C), and he was given nivolumab as a third-line therapy. After 3 cycles of nivolumab, his primary lesion was enlarged and pleural effusion was increased, although his pleural dissemination was reduced; thus, DR was diagnosed. His overall tumor assessment by RECIST was SD and that by iRECIST was iSD, and nivolumab treatment 
was continued. After 3 additional cycles of nivolumab, his primary lesion enlarged and was diagnosed as RECIST-defined PD.

A summary of the patients' clinical courses is shown in Figure 3 and Supplementary Table 1. At DR diagnosis, 2 patients showed RECIST-defined PD and 3 patients showed RECIST-defined SD. The PD-L1 TPSs for these patients were 10\% (No. 6), 30\% (No. 28), $0 \%$ (No. 40), unknown because of low amount of specimen (No. 62), and 1\% (No. 65). The times to treatment failure from commencement of nivolumab were $729,234,100,174$, and 151 days, respectively. Of the 5 patients, 2 achieved a durable clinical benefit. In this cohort, all patients continued nivolumab after DR, and local therapy was not conducted for the progressive lesion.

\section{Pathological analysis of the DR site}

Of the 5 patients with DR, 2 consented to tumor biopsies of the growing lesion (No. 40 and No. 65). In Patient No. 40, adenocarcinoma was diagnosed in the cell block analysis of the pleural effusion (Supplementary Figure 1A), which showed the same histology as the primary lesion (Supplementary Figure 1B). There was no evidence of other etiologies of pleural effusion, such as infection. Patient No. 65 underwent kidney biopsy, which revealed adenocarcinoma (Supplementary Figure 1C). Interestingly, this patient had an adenosquamous histology in the primary lesion (Supplementary Figure 1D); thus, a histological temporal heterogeneity was found between the primary and metastatic lesion.

\section{Response patterns and OS}

Patients showing DR had significantly longer OS than those showing concordant PD (PD without DR) (46.9 vs. 8.2 months, respectively; $p=0.038$ ). In addition, there was no significant difference in the OS between patients who showed concordant PR (PR without DR) and those who showed concordant SD (SD without $D R$ ) (not reached and 19.3, respectively; $p=0.24$ and $p=0.76$, respectively). The datas and Kaplan-Meier curves for OS are shown in Figure 4 and Supplementary table 2.

\section{Comparison between ICI, chemotherapy, and TKI treatment}

There were 150 patients in the chemotherapy group and 92 patients in the TKI group, and the frequencies of DR were $1 \%(2 / 150)$ and $4 \%(4 / 92)$, respectively (Supplementary Figure 2). Increased frequencies of DR were observed in the ICl and TKI groups compared with that in the chemotherapy group; however, the differences were not statistically significant. None of the patients in the chemotherapy and TKI cohorts achieved durable clinical benefit.

\section{Discussion}

Our study evaluated the occurrence of DR after commencing nivolumab treatment in patients with previously treated NSCLC. We evaluated the patient characteristics, treatment course after DR, and histological findings and compared the prevalence of DR in the nivolumab treatment cohort with those in 
the chemotherapy and TKI cohorts. To the best of our knowledge, this is the first comprehensive report of DR of ICl monotherapy describing the prognostic benefit of DR.

In our study, $5 \%$ of patients with NSCLC exhibited DR after starting nivolumab treatment, and this response was observed across all organs. The DR was first described as a "mixed response" in melanoma patients in a prospective clinical trial of immunotherapy [22]. Moreover, DR was also observed in a retrospective study of NSCLC cases with a frequency of 7.5\% [12]. Importantly, DR is a different phenomenon than pseudoprogression. Pseudoprogression is typically defined as the initial increase of tumor size or the presence of new lesions prior to a decrease in size [6]. In our cohorts, none of our DR cases showed a decrease in size, and all remained SD. Taken together, we speculate that DR is a distinctive response pattern of $\mathrm{ICI}$ monotherapy, irrespective of the cancer type or organ involved.

Such response patterns present a particular challenge for patient management, in terms of whether the patient should switch to next-line treatment, continue the original regimen, be followed-up frequently, or commence local therapy. In our cohort, all patients who exhibited DR continued nivolumab treatment, and $40 \%$ of patients (Patients No. 6 and No. 28) achieved a durable clinical benefit [20]. Moreover, better survival was observed in patients with DR than in patients with concordant PD. In previous studies, ICI benefits were observed in $20-50 \%$ of patients who exhibited DR [11,12]. We should be aware that DR does not always represent ICI resistance, and switching ICI treatment to another systemic chemotherapy defined according to RECIST ver1.1 may be an early decision. However, continuing ICI in carefully selected patients whose clinical conditions are stable and who have not experienced severe toxicities is a possible treatment option. Taken together, using the iRECIST guideline, developed to avoid the underestimations of RECIST ver1.1, may be a better strategy. There is need for further investigation into the potential benefits and risks of DR in patients who continue immunotherapy.

The underlying mechanisms for a DR have not been understood. A possible explanation is that DR results from immune reactions, such as massive immune cell infiltrations or the sarcoid reaction, which have been reported in previous studies [23,24]. A second possible explanation is that the temporal heterogeneity of the tumor, such as the PD-L1 TPS and immune status, may account for the DR [25]. In our cohort, no specific immune reactions were observed, and one patient exhibited tumor histology heterogeneity between primary and metastatic lesions.

The DR was previously reported as a relatively common phenomenon in acquired resistance following EGFR TKI monotherapy for EGFR mutation positive NSCLC (identified in $20 \%$ of patients), and the mechanism was speculated to be the genetic or tumoral heterogeneity [26-29]. The previously reported prevalence is higher than that in our findings, as the radiologic definition is not same. Importantly, DR was considered an independent worse predictive factor in the TKI cohort, and we did not observe any clinical benefit in patients who received chemotherapy or TKI treatment in this study. We should recognize that the clinical significance of DR occurring during chemotherapy or TKI therapy is different from that occurring during $\mathrm{ICl}$ therapy. 
Our study may contribute in establishing appropriate management plans for patients who exhibit DR during ICl treatment; however, it has several limitations. First, it was a retrospective study that included a small number of subjects from a single institution, owing to the rarity of DR. Second, all patients received nivolumab after DR, and we have no data on patients who stopped ICls or commenced local ablative therapy.

\section{Conclusions}

DR was an uncommon but distinctive response pattern in nivolumab monotherapy, and a durable benefit was observed in patients exhibiting a DR. The survival benefit in DR cases was better than in concordant PD cases. These data provide scope for improving ICI therapy for NSCLC patients. Thus, in patients presenting DR, continuing nivolumab therapy may be beneficial and may allow patients to achieve a longer OS. Further research is required to elucidate the characteristics, treatment strategies, and underlying mechanisms of DR.

\section{Abbreviations}

$\mathrm{CR}=$ complete response; $\mathrm{DR}=$ dissociated response; $\mathrm{ECOG}-\mathrm{PS}=$ Eastern Cooperative Oncology Group performance status; EGFR=epidermal growth factor receptor; ICI=immune checkpoint inhibitor; NSCLC=non-small cell lung cancer; $O S=$ overall survival; $P D=$ progressive disease; $P D-1=$ programmed death protein 1; PD-L1=programmed death ligand 1; PR=partial response; RECIST=Response Evaluation Criteria in Solid Tumors; $S D=$ stable disease; $S L D=$ sum of the longest diameter; TPS=tumor proportion score; $\mathrm{TKI}=$ tyrosine kinase inhibitor; iUPD=unconfirmed progressive disease

\section{Declarations}

\section{Funding}

This research did not receive any specific grant from funding agencies in the public, commercial, or notfor-profit sectors.

\section{Competing interests}

Dr. Sato has received lecture fees from Ono Pharmaceutical Co., Ltd. (Osaka, Japan). Dr. Morimoto has received manuscript preparation fees and was on an advisory board of Bristol-Myers Squibb K.K. (Tokyo, Japan). Dr Hosoya has received lecture fees from Ono Pharmaceutical Co., Ltd. (Osaka, Japan). All remaining authors have no conflicts of interest to declare. We wish to confirm that there are no other known conflicts of interest associated with this publication. Further, there was no significant financial support for this work that could have influenced its outcome.

\section{Ethics approval and consent to participate}


This study was conducted with the approval of the Kobe City Medical Center General Hospital Ethics Committee (No. zn190108).

\section{Consent for publication}

Informed consent was not required owing to the retrospective nature of the study.

\section{Availability of data and materials}

All datasets on which the conclusions of this paper rely are available on request.

\section{Authors' contributions}

Yuki Sato: guarantor of the paper and responsible for the integrity of the work as a whole, from inception to the published article. Takeshi Morimoto data analysis, interpretation, and revision of manuscript.

Shigeo Hara: conducted pathological analysis. Kazuma Nagata: study conception and design. Kazutaka Hosoya, Atsushi Nakagawa, Ryo Tachikawa, and Keisuke Tomii: data acquisition and radiological assessment. All authors have read and approved the manuscript as submitted.

\section{Acknowledgements}

The authors would like to thank Keiko Sakuragawa and Kanako Masuta for her administrative assistance, and Yukihiro Imai for conducting the pathological analyses. We would like to thank Editage (www.editage.com) for English language editing.

\section{References}

1. Siegel RL, Miller KD, Jemal A (2019) Cancer statistics, 2019. CA Cancer J Clin 69 (1):7-34. doi:10.3322/caac. 21551

2. Molina JR, Yang P, Cassivi SD, Schild SE, Adjei AA (2008) Non-small cell lung cancer: epidemiology, risk factors, treatment, and survivorship. Mayo Clin Proc 83 (5):584-594. doi:10.4065/83.5.584

3. Brahmer J, Reckamp KL, Baas P, Crino L, Eberhardt WE, Poddubskaya E, Antonia S, Pluzanski A, Vokes EE, Holgado E, Waterhouse D, Ready N, Gainor J, Aren Frontera O, Havel L, Steins M, Garassino MC, Aerts JG, Domine M, Paz-Ares L, Reck M, Baudelet C, Harbison CT, Lestini B, Spigel DR (2015) Nivolumab versus Docetaxel in Advanced Squamous-Cell Non-Small-Cell Lung Cancer. N Engl J Med 373 (2):123-135. doi:10.1056/NEJMoa1504627

4. Borghaei H, Paz-Ares L, Horn L, Spigel DR, Steins M, Ready NE, Chow LQ, Vokes EE, Felip E, Holgado E, Barlesi F, Kohlhaufl M, Arrieta O, Burgio MA, Fayette J, Lena H, Poddubskaya E, Gerber DE, Gettinger SN, Rudin CM, Rizvi N, Crino L, Blumenschein GR, Jr., Antonia SJ, Dorange C, Harbison CT, Graf Finckenstein F, Brahmer JR (2015) Nivolumab versus Docetaxel in Advanced Nonsquamous NonSmall-Cell Lung Cancer. N Engl J Med 373 (17):1627-1639. doi:10.1056/NEJMoa1507643 
5. Borcoman E, Kanjanapan Y, Champiat S, Kato S, Servois V, Kurzrock R, Goel S, Bedard P, Le Tourneau C (2019) Novel patterns of response under immunotherapy. Ann Oncol 30 (3):385-396. doi:10.1093/annonc/mdz003

6. Fujimoto D, Yoshioka H, Kataoka Y, Morimoto T, Hata T, Kim YH, Tomii K, Ishida T, Hirabayashi M, Hara S, Ishitoko M, Fukuda Y, Hwang MH, Sakai N, Fukui M, Nakaji H, Morita M, Mio T, Yasuda T, Sugita T, Hirai T (2019) Pseudoprogression in Previously Treated Patients with Non-Small Cell Lung Cancer Who Received Nivolumab Monotherapy. J Thorac Oncol 14 (3):468-474. doi:10.1016/j.jtho.2018.10.167

7. Katz SI, Hammer M, Bagley SJ, Aggarwal C, Bauml JM, Thompson JC, Nachiappan AC, Simone CB, 2nd, Langer CJ (2018) Radiologic Pseudoprogression during Anti-PD-1 Therapy for Advanced NonSmall Cell Lung Cancer. J Thorac Oncol 13 (7):978-986. doi:10.1016/j.jtho.2018.04.010

8. Champiat S, Dercle L, Ammari S, Massard C, Hollebecque A, Postel-Vinay S, Chaput N, Eggermont A, Marabelle A, Soria JC, Ferte C (2017) Hyperprogressive Disease Is a New Pattern of Progression in Cancer Patients Treated by Anti-PD-1/PD-L1. Clin Cancer Res 23 (8):1920-1928. doi:10.1158/10780432.CCR-16-1741

9. Kim CG, Kim KH, Pyo KH, Xin CF, Hong MH, Ahn BC, Kim Y, Choi SJ, Yoon HI, Lee JG, Lee CY, Park SY, Park SH, Cho BC, Shim HS, Shin EC, Kim HR (2019) Hyperprogressive disease during PD-1/PD-L1 blockade in patients with non-small-cell lung cancer. Ann Oncol 30:1104-1131. doi:10.1093/annonc/mdz123

10. Wolchok JD, Hoos A, O'Day S, Weber JS, Hamid O, Lebbe C, Maio M, Binder M, Bohnsack O, Nichol G, Humphrey R, Hodi FS (2009) Guidelines for the Evaluation of Immune Therapy Activity in Solid Tumors: Immune-Related Response Criteria. Clinical Cancer Research 15 (23):7412-7420. doi:10.1158/1078-0432.ccr-09-1624

11. Tabatabai R, Natale R (2018) Immunotherapy and Mixed Radiographic Response in Non-Small Cell Lung Cancer. J Cancer Clin 1 (1):1005

12. Tazdait M, Mezquita L, Lahmar J, Ferrara R, Bidault F, Ammari S, Balleyguier C, Planchard D, Gazzah A, Soria JC, Marabelle A, Besse B, Caramella C (2018) Patterns of responses in metastatic NSCLC during PD-1 or PDL-1 inhibitor therapy: Comparison of RECIST 1.1, irRECIST and iRECIST criteria. Eur J Cancer 88:38-47. doi:10.1016/j.ejca.2017.10.017

13. Nishino M, Dahlberg SE, Adeni AE, Lydon CA, Hatabu H, Janne PA, Hodi FS, Awad MM (2017) Tumor Response Dynamics of Advanced Non-small Cell Lung Cancer Patients Treated with PD-1 Inhibitors: Imaging Markers for Treatment Outcome. Clin Cancer Res 23 (19):5737-5744. doi:10.1158/10780432.CCR-17-1434

14. Goldstraw P, Chansky K, Crowley J, Rami-Porta R, Asamura H, Eberhardt WE, Nicholson AG, Groome P, Mitchell A, Bolejack V, International Association for the Study of Lung Cancer S, Prognostic Factors Committee AB, Participating I, International Association for the Study of Lung Cancer S, Prognostic Factors Committee Advisory B, Participating I (2016) The IASLC Lung Cancer Staging Project: 
Proposals for Revision of the TNM Stage Groupings in the Forthcoming (Eighth) Edition of the TNM Classification for Lung Cancer. J Thorac Oncol 11 (1):39-51. doi:10.1016/j.jtho.2015.09.009

15. Nagai Y, Miyazawa H, Huqun, Tanaka T, Udagawa K, Kato M, Fukuyama S, Yokote A, Kobayashi K, Kanazawa M, Hagiwara K (2005) Genetic heterogeneity of the epidermal growth factor receptor in non-small cell lung cancer cell lines revealed by a rapid and sensitive detection system, the peptide nucleic acid-locked nucleic acid PCR clamp. Cancer Res 65 (16):7276-7282. doi:10.1158/00085472.CAN-05-0331

16. Vanderlaan PA, Yamaguchi N, Folch E, Boucher DH, Kent MS, Gangadharan SP, Majid A, Goldstein MA, Huberman MS, Kocher ON, Costa DB (2014) Success and failure rates of tumor genotyping techniques in routine pathological samples with non-small-cell lung cancer. Lung Cancer 84 (1):3944. doi:10.1016/j.lungcan.2014.01.013

17. Roach C, Zhang N, Corigliano E, Jansson M, Toland G, Ponto G, Dolled-Filhart M, Emancipator K, Stanforth D, Kulangara K (2016) Development of a Companion Diagnostic PD-L1 Immunohistochemistry Assay for Pembrolizumab Therapy in Non-Small-cell Lung Cancer. 24 (6):392-397. doi:10.1097/pai.0000000000000408

18. Eisenhauer EA, Therasse P, Bogaerts J, Schwartz LH, Sargent D, Ford R, Dancey J, Arbuck S, Gwyther S, Mooney M, Rubinstein L, Shankar L, Dodd L, Kaplan R, Lacombe D, Verweij J (2009) New response evaluation criteria in solid tumours: revised RECIST guideline (version 1.1). Eur J Cancer 45 (2):228247. doi:10.1016/j.ejca.2008.10.026

19. Seymour L, Bogaerts J, Perrone A, Ford R, Schwartz LH, Mandrekar S, Lin NU, Litière S, Dancey J, Chen A, Hodi FS, Therasse P, Hoekstra OS, Shankar LK, Wolchok JD, Ballinger M, Caramella C, De Vries EGE (2017) iRECIST: guidelines for response criteria for use in trials testing immunotherapeutics. The Lancet Oncology 18 (3):e143-e152. doi:10.1016/s1470-2045(17)30074-8

20. Hong L, Negrao MV, Dibaj SS, Chen R, Reuben A, Bohac JM, Liu X, Skoulidis F, Gay CM, Cascone T, Mitchell KG, Tran HT, Le X, Byers LA, Sepesi B, Altan M, Elamin YY, Fossella FV, Kurie JM, Lu C, Mott FE, Tsao AS, Rinsurongkawong W, Lewis J, Gibbons DL, Glisson BS, Blumenschein GR, Jr., Roarty EB, Futreal PA, Wistuba, II, Roth JA, Swisher SG, Papadimitrakopoulou VA, Heymach JV, Lee JJ, Simon GR, Zhang J (2020) Programmed Death Ligand 1 Heterogeneity and its Impact on Benefit from Immune Checkpoint Inhibitors in Non-Small-Cell Lung Cancer. J Thorac Oncol:S15560864(1520)30373-30377. doi:10.1016/j.jtho.2020.04.026

21. Lee Y, Kim HY, Lee SH, Lim KY, Lee GK, Yun T, Han JY, Kim HT, Lee JS (2014) Clinical significance of heterogeneity in response to retreatment with epidermal growth factor receptor tyrosine kinase inhibitors in patients with lung cancer acquiring secondary resistance to the drug. Clin Lung Cancer 15 (2):145-151. doi:10.1016/j.cllc.2013.11.008

22. Kruit WH, van Ojik HH, Brichard VG, Escudier B, Dorval T, Dreno B, Patel P, van Baren N, Avril MF, Piperno S, Khammari A, Stas M, Ritter G, Lethe B, Godelaine D, Brasseur F, Zhang Y, van der Bruggen P, Boon T, Eggermont AM, Marchand M (2005) Phase 1/2 study of subcutaneous and intradermal immunization with a recombinant MAGE-3 protein in patients with detectable metastatic melanoma. Int J Cancer 117 (4):596-604. doi:10.1002/ijc.21264 
23. Jespersen H, Bjursten S, Ny L, Levin M (2018) Checkpoint inhibitor-induced sarcoid reaction mimicking bone metastases. The Lancet Oncology 19 (6):e327. doi:10.1016/s1470-2045(18)302523

24. Gkiozos I, Kopitopoulou A, Kalkanis A, Vamvakaris IN, Judson MA, Syrigos KN (2018) SarcoidosisLike Reactions Induced by Checkpoint Inhibitors. J Thorac Oncol 13 (8):1076-1082. doi:10.1016/j.jtho.2018.04.031

25. Osorio JC, Arbour KC, Le DT, Durham JN, Plodkowski AJ, Halpenny DF, Ginsberg MS, Sawan P, Crompton JG, Yu HA, Namakydoust A, Nabet BY, Chaft JE, Riely GJ, Rizvi H, Diaz LA, Hellmann MD (2019) Lesion-Level Response Dynamics to Programmed Cell Death Protein (PD-1) Blockade. Journal of Clinical Oncology 37 (36):3546-3555. doi:10.1200/jco.19.00709

26. Remon J, Majem M (2013) EGFR mutation heterogeneity and mixed response to EGFR tyrosine kinase inhibitors of non small cell lung cancer: a clue to overcoming resistance. Transl Lung Cancer Res 2 (6):445-448. doi:10.3978/j.issn.2218-6751.2013.10.14

27. Shinno Y, Goto Y, Sato J, Morita R, Matsumoto Y, Murakami S, Kanda S, Horinouchi H, Fujiwara Y, Yamamoto N, Ohe Y (2019) Mixed response to osimertinib and the beneficial effects of additional local therapy. Thorac Cancer 10 (4):738-743. doi:10.1111/1759-7714.12991

28. Dong ZY, Zhai HR, Hou QY, Su J, Liu SY, Yan HH, Li YS, Chen ZY, Zhong WZ, Wu YL (2017) Mixed Responses to Systemic Therapy Revealed Potential Genetic Heterogeneity and Poor Survival in Patients with Non-Small Cell Lung Cancer. Oncologist 22 (1):61-69. doi:10.1634/theoncologist.20160150

29. Chen ZY, Zhong WZ, Zhang XC, Su J, Yang XN, Chen ZH, Yang JJ, Zhou Q, Yan HH, An SJ, Chen HJ, Jiang BY, Mok TS, Wu YL (2012) EGFR mutation heterogeneity and the mixed response to EGFR tyrosine kinase inhibitors of lung adenocarcinomas. Oncologist 17 (7):978-985.

doi:10.1634/theoncologist.2011-0385

\section{Tables}

Table 1. Patient characteristics 


\begin{tabular}{|c|c|c|c|c|}
\hline & $\begin{array}{l}\text { Total } \\
(\%)\end{array}$ & $\begin{array}{l}\text { Dissociated response } \\
(N=5)\end{array}$ & $\begin{array}{l}\text { Concordant response } \\
(N=102)\end{array}$ & $\begin{array}{l}P \text { - } \\
\text { value }\end{array}$ \\
\hline & \multicolumn{4}{|l|}{$(N=107)$} \\
\hline \multicolumn{5}{|l|}{ Age (years) } \\
\hline Mean (SD) & $\begin{array}{l}68.2 \\
(9.6)\end{array}$ & $69.2(10.3)$ & $68.2(9.6)$ & 0.81 \\
\hline \multicolumn{5}{|l|}{ Sex } \\
\hline Male & $77(72)$ & $3(60)$ & $74(73)$ & \multirow[t]{2}{*}{0.62} \\
\hline Female & $30(28)$ & $2(40)$ & $28(27)$ & \\
\hline \multicolumn{5}{|l|}{ Smoking status } \\
\hline Never & $27(25)$ & $2(40)$ & $25(25)$ & \multirow[t]{2}{*}{0.60} \\
\hline Current or former & $80(75)$ & $3(60)$ & $77(75)$ & \\
\hline \multicolumn{5}{|l|}{ Histology } \\
\hline Adenocarcinoma & $79(74)$ & $4(80)$ & $75(74)$ & \multirow[t]{3}{*}{$1.00 *$} \\
\hline $\begin{array}{l}\text { Squamous cell } \\
\text { carcinoma }\end{array}$ & $22(21)$ & $0(0)$ & $22(22)$ & \\
\hline Others & $6(6)$ & $1(20)$ & $5(5)$ & \\
\hline \multicolumn{5}{|l|}{ ECOG PS } \\
\hline 0 or 1 & $99(93)$ & $5(100)$ & $94(92)$ & \multirow[t]{2}{*}{1.00} \\
\hline 2 & $8(7)$ & $0(0)$ & $8(8)$ & \\
\hline \multicolumn{5}{|l|}{ Stage } \\
\hline IIIB & $7(7)$ & $0(0)$ & $7(7)$ & \multirow[t]{2}{*}{1.00} \\
\hline IV & $\begin{array}{l}100 \\
(93)\end{array}$ & $5(100)$ & $95(93)$ & \\
\hline \multicolumn{5}{|l|}{ Mutation status } \\
\hline EGFR or $A L K$ positive & $19(18)$ & $1(20)$ & $18(18)$ & \multirow[t]{2}{*}{1.00} \\
\hline $\begin{array}{l}\text { Wild-type or } \\
\text { uninvestigated }\end{array}$ & $88(82)$ & $4(80)$ & $84(82)$ & \\
\hline \multicolumn{5}{|l|}{ Prior therapy } \\
\hline 1 prior therapy & $51(48)$ & $2(40)$ & $49(48)$ & \multirow[t]{2}{*}{1.00} \\
\hline$\geq 2$ prior therapies & $56(52)$ & $3(60)$ & $53(52)$ & \\
\hline
\end{tabular}




\begin{tabular}{|llll|}
\hline RECIST & & \\
\hline CR & $0(0)$ & $0(0)$ & $0(0)$ \\
\hline PR & $24(22)$ & $0(0)$ & $24(24)$ \\
SD & $20(19)$ & $2(40)$ & $18(18)$ \\
PD & $63(59)$ & $3(60)$ & $60(59)$ \\
\hline
\end{tabular}

SD: standard deviation; ECOG PS: Eastern Cooperative Oncology Group Performance Status; EGFR: epidermal growth factor receptor; $A L K$ : anaplastic lymphoma kinase; RECIST: Response Evaluation Criteria in Solid Tumors; CR: complete response; PR: partial response; SD: stable disease; PD: progressive disease

* Comparison between adenocarcinoma and non-adenocarcinoma

\section{Figures}

Figure 1

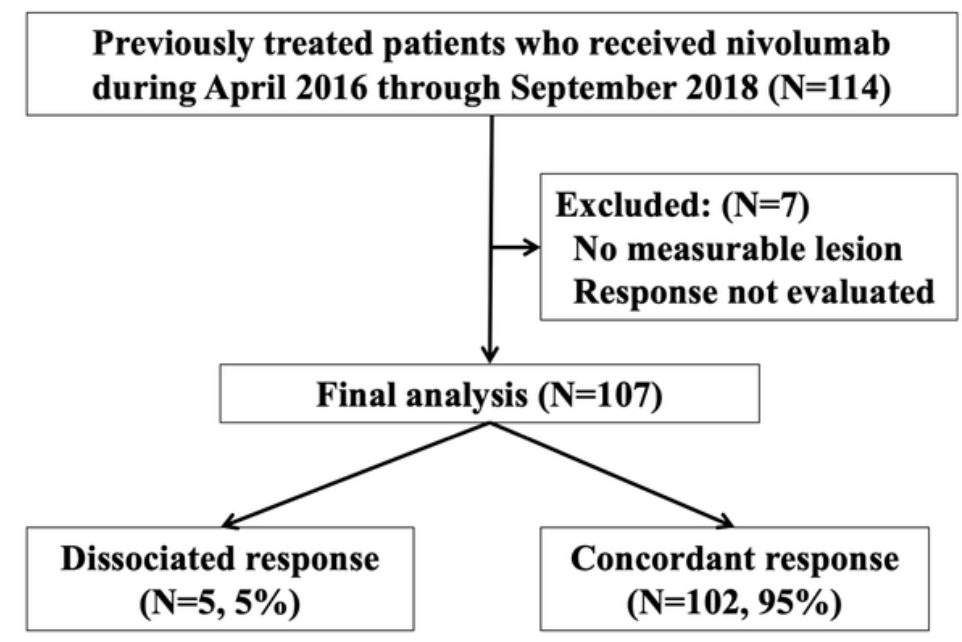

\section{Figure 1}

Study flow chart. This study included 107 patients. Of them, 5 (5\%) patients experienced a dissociated response, and 102 patients had a concordant response (partial response, stable disease, and progressive disease without dissociated response). 

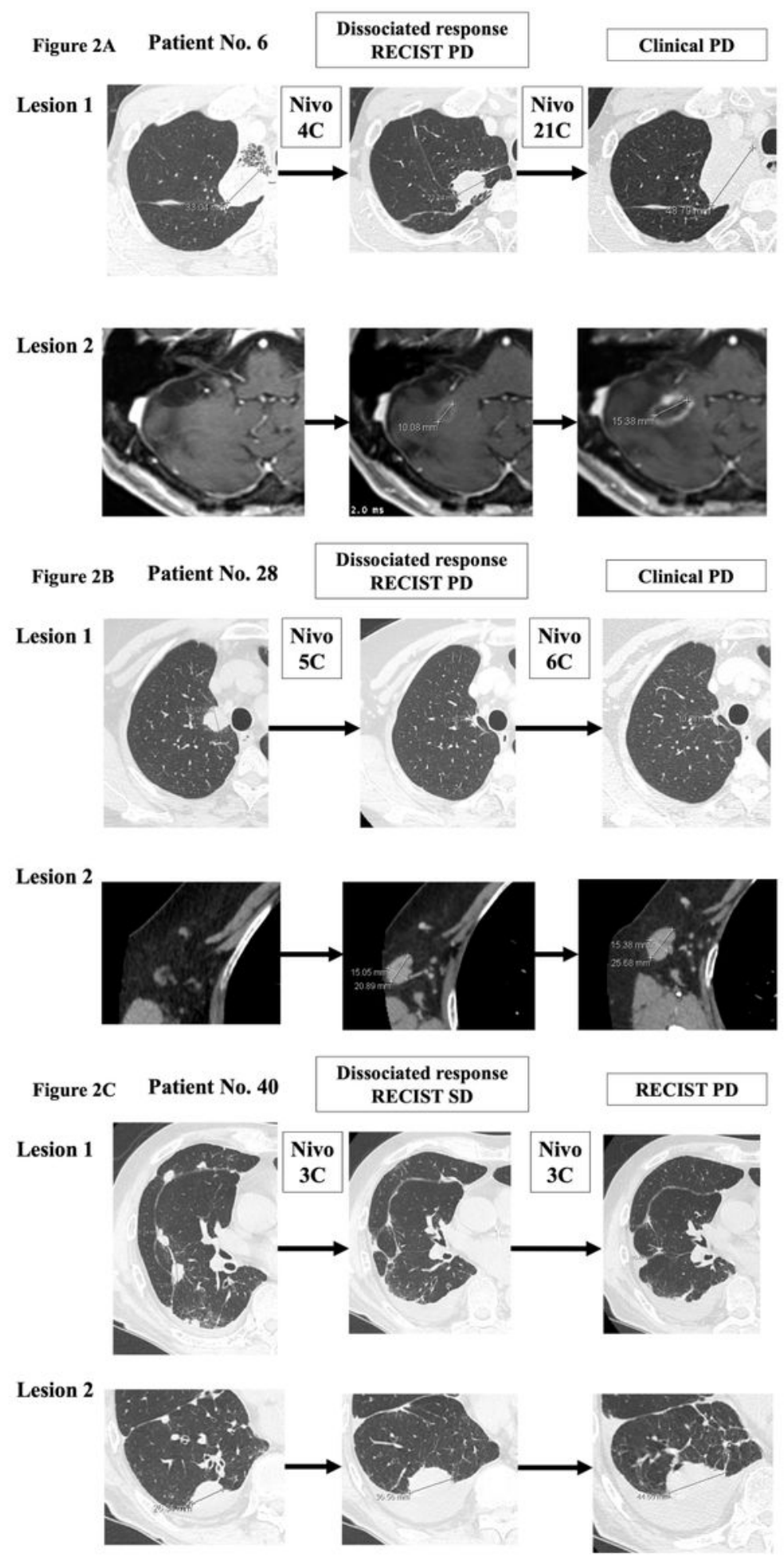

\section{Figure 2}

Representative radiological data of patients with dissociated responses (A-C). Nivo: nivolumab; RECIST: Response Evaluation Criteria in Solid Tumors; PD: progressive disease 
Figure 3

Patient No.

6

Nivo 4

$\downarrow$

Nivo 21

(AE)

\section{DR}

28 Nivo 5

Clinical PD

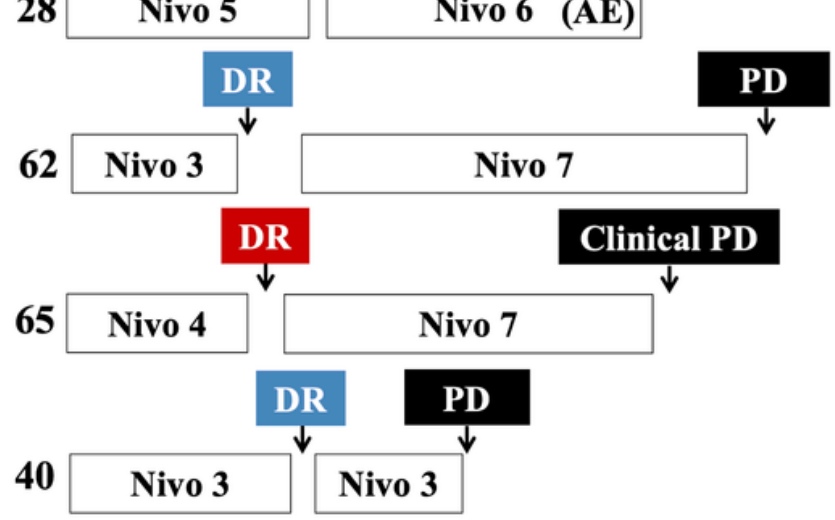

0

100

200

300

700

\section{DR}

RECIST PD

DR

RECIST SD

Figure 3

Clinical courses of patients with a dissociated response. Nivo: nivolumab; DR: dissociated response; AE: adverse effect; RECIST: Response Evaluation Criteria in Solid Tumors; PD: progressive disease
Figure 4
A. Concordant PR $(n=24)$
C. Concordant SD $(n=18)$
B. Dissociated response $(n=5)$
D. Concordant PD $(n=60)$

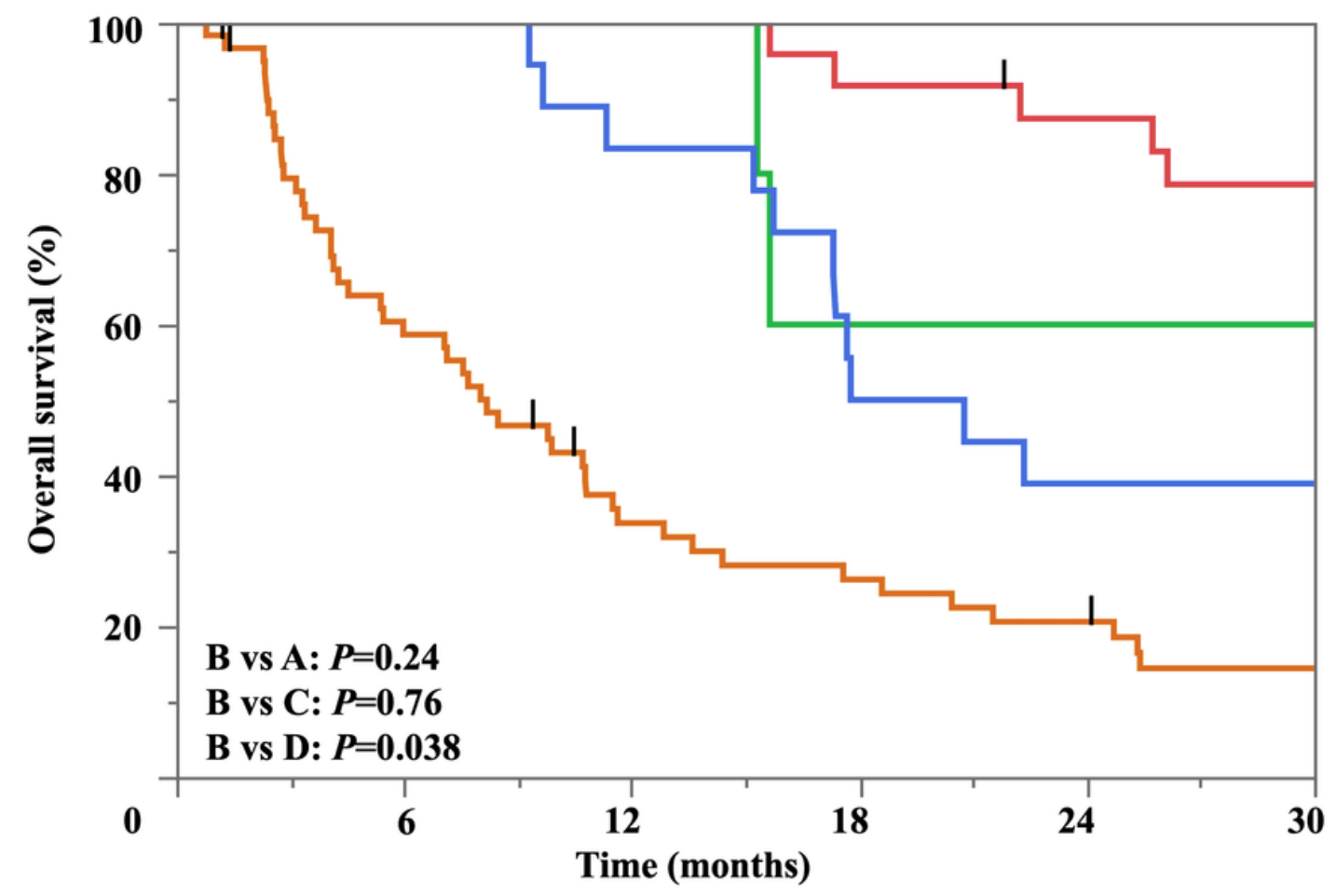


Figure 4

Kaplan-Meier survival curves showing the overall survival stratified by tumor response. PR: partial response; SD: stable disease; PD: progressive disease

\section{Supplementary Files}

This is a list of supplementary files associated with this preprint. Click to download.

- SupplementaryTable1and2.docx

- supp.fig1.jpg

- supp.fig2.jpg 